\title{
Transcriptome Analysis of Ten-DPA Fiber in an Upland Cotton (Gossypium hirsutum) Line with Improved Fiber Traits from Phytochrome A1 RNAi Plants
}

\author{
Qing Miao', Peng Deng', Sukumar Saha ${ }^{3}$, Johnie N. Jenkins' ${ }^{3}$, Chuan-Yu Hsu4, \\ Ibrokhim Y. Abdurakhmonov ${ }^{5}$, Zabardast T. Buriev5, Alan Pepper6, Din-Pow Ma1 ${ }^{*}$
}

\author{
${ }^{1}$ Department of Biochemistry, Molecular Biology, Entomology and Plant Pathology, Mississippi State University, Mississippi State, \\ MS, USA \\ ${ }^{2}$ Department of Pharmacology, Weill Cornell Medical College, New York, NY, USA \\ ${ }^{3}$ USDA-ARS, Crop Science Research Laboratory, Mississippi State, MS, USA \\ ${ }^{4}$ Institute for Genomics, Biocomputing and Biotechnology, Mississippi State University, Mississippi State, MS, USA \\ ${ }^{5}$ Center of Genomics and Bioinformatics, Academy of Sciences of Uzbekistan, Tashkent, Uzbekistan \\ ${ }^{6}$ Department of Biology, Texas A \& M University, College Station, TX, USA \\ Email:^dma@bch.msstate.edu
}

How to cite this paper: Miao, Q., Deng, P., Saha, S., Jenkins, J.N., Hsu, C.-Y., Abdurakhmonov, I.Y., Buriev, Z.T., Pepper, A. and Ma, D.-P. (2017) Transcriptome Analysis of Ten-DPA Fiber in an Upland Cotton (Gossypium hirsutum) Line with Improved Fiber Traits from Phytochrome A1 RNAi Plants. American Journal of Plant Sciences, 8, 2530-2553.

https://doi.org/10.4236/ajps.2017.810172

Received: August 7, 2017

Accepted: September 25, 2017

Published: September 28, 2017

Copyright ( 92017 by authors and Scientific Research Publishing Inc. This work is licensed under the Creative Commons Attribution International License (CC BY 4.0).

http://creativecommons.org/licenses/by/4.0/ (c) (i) Open Access

\begin{abstract}
Silencing phytochrome A1 gene (PHYA1) by RNA interference in Upland cotton (Gossypium hirsutum L. cv. Coker 312) had generated PHYA1 RNAi lines with improved fiber quality (longer, stronger and finer fiber). To reveal molecular mechanisms that govern fiber development with positive fiber traits, a study of global gene expression profiling of 10-DPA fibers in a PHYA1 RNAi line and its parent Coker 312 was conducted by high-throughput RNA sequencing. A comparative analysis of transcriptomes between the two lines had identified 142 genes that were differentially expressed in the 10-DPA fiber of the RNAi line. Gene Ontology analysis showed that these differentially expressed genes were mainly involved in metabolic pathways, heterocyclic/organic cyclic compound binding and multiple enzyme activities, and cell structures which were reported to play important roles in fiber development. Twenty-eight KEGG pathways were mapped for the 142 genes, and the pathways related to glycolysis/gluconeogenesis and pyruvate metabolism were the most abundant and followed by cytochrome P450-involved pathways, suggesting that fiber improvement could be through the regulation of proteins involved in cytochrome P450 pathways. Genes encoding WRKY transcription factors, sucrose synthase, xyloglucan endotransglucosylase hydrolase, udp-glucuronate: $x y-$ lan alpha-glucuronosyltransferase, and genes involved in lipid metabolism and
\end{abstract}


$\mathrm{ABA} / \mathrm{brassinosteroid} \mathrm{signal} \mathrm{transduction} \mathrm{pathways} \mathrm{were} \mathrm{found} \mathrm{differentially}$ expressed in the RNAi line. These genes have direct impacts on cotton fiber quality. The results of this study elucidate molecular signatures and possible mechanisms of fiber improvement in the background of PHYA1 RNAi in cotton and should help for future fine-tuning and programming of cotton fiber development.

\section{Keywords}

Fiber Development, Phytochrome A1, RNA Interference, RNA-Seq, Transcriptome

\section{Introduction}

Cotton is the most important textile fiber and also an important oilseed crop [1], providing significant economic impact as a major cash crop in 70 counties around the world [2]. The cotton industry demands to produce cotton with good fiber qualities, including longer and finer fiber with high fiber strength. Most of these desirable fiber traits are controlled by many genes (QTLs) and are very difficult to improve simultaneously by conventional breeding program because some of these traits are inversely related. Cotton fiber is a single cell derived from the epidermal layer of the ovule of a cotton seed, and its development consists of four overlapping stages: initiation, elongation (primary wall biosynthesis), secondary wall biosynthesis and maturation [3]. The elongation stage encompasses the major expansion growth phase of the fiber, which may last for 25 to 30 days post anthesis (DPA) [4]. During elongation, fiber deposits a thin, expandable primary cell wall composed of a variety of carbohydrate polymers [5]. As the fiber approaches the end of elongation, the major phase of secondary wall synthesis starts [3].

Previous studies showed that silencing phytochrome A1 gene (PHYA1) by RNA interference generated RNAi cotton lines with improved fiber quality (longer, stronger and finer fiber) and some other phenotypic changes, including early-flowering, vigorous root and vegetative growth, without adverse effects on yield and fiber development, and higher tolerance to abiotic stresses when compared to non-transformed Coker 312 [6] [7]. Phytochromes are red and far-red light photoreceptors, and a high ratio of far-red light to red light perceived by the photoreceptors increased fiber length [8]. Phytochromes were reported to mediate plant hormone signaling through direct interaction between their negative regulators phytochrome-interacting factors (PIFs) and certain phytohormone signaling components, such as DELLA proteins [9]. Phytohormones play roles in mediating cotton fiber development. Auxins and gibberellins (GA3) promote early stages of fiber initiation and have a positive effect on fiber elongation [10]. Abscisic acid (ABA) inhibits fiber initiation by counteracting the promotion of auxins and gibberellins [10]. Ethylene (ET) plays an important role 
in promoting fiber cell elongation [10]. In addition, ET- and brassinosteroid (BR)-related genes are up-regulated during fiber elongation [11]. Over the past decades, many genes have been reported to be involved in cotton fiber development. Genes encoding MYB transcription factors play a role in fiber cell fate determination and development [12]. Fiber cells in elongation stage are dynamically changed both in components and structures. Many genes involved in carbohydrate metabolism and transportation are up-regulated during fiber development [12]. The development of fiber cells also depends on higher turgor pressure, and enzymes and proteins for maintaining high turgor pressure are enriched in growing fiber cells [12]. In addition, wall-loosening proteins also play roles in fiber elongation [12]. Recently, genome-wide analyses of gene expression via comparative transcriptome profiling have identified many genes that are differentially expressed in fiber cells at the four developmental stages [13] [14].

In this study, high-throughput RNA sequencing, a powerful tool, was used to uncover how silencing the $P H Y A 1$ gene could lead to the improvement of fiber quality and agricultural traits in the RNAi line. A total of 142 genes were found to be differentially expressed in PHYA1 RNAi cotton compared to Coker 312 . GO (Gene Ontology) and KEGG (Kyoto Encyclopedia of Genes and Genomes) analysis suggested that improved fiber quality of RNAi cotton might be due to the regulation of some critical transcription factors and genes involved in carbohydrate metabolism and phytohormone signaling. Cytochrome P450 involved pathways and other differentially expressed genes (DEGs) might play a crucial role in fiber and abiotic tolerance improvement of RNAi plants. The identified and characterized genes that were differentially expressed in PHYA1 RNAi cotton lines provided useful information for future fine-tuning and better genetic improvement of cotton.

\section{Materials and Methods}

\subsection{Plant Materials and Plant Growth}

With the aim to analyze the function of phytochrome A1 gene (PHYA1) of cotton in association with fiber length [15], a binary RNAi construct was previously developed by PCR amplification of the 213 bp hinge region of $P H Y A 1$ gene from G. hirsutum TM-1 genomic DNA and cloned into the PHellsgate- 8 vector using the Gateway Cloning System (Thermo Fisher Scientific) [6]. The RNAi construct was then somatically transformed into embryogenic Gossypium hirsutum L. cv. Coker 312 to generate transgenic cotton plants [6]. The resulting PHYA1-specific single-seed decent RNAi transgenic plants were subsequently self-pollinated through first to sixth generations (T1-7-6) and followed by selection of individual plants in each generation for phytochrome-associated traits (including plant architecture, hypocotyl length, vigorous growth, early flowering, superior fiber quality, etc.) and genomic insertions of the RNAi hairpin construct. The RNAi plants of T2-6 generations were then grown in field stations at Tashkent, Uzbe- 
kistan under normal solar light conditions and evaluated for agronomic performance and stability of the RNAi effects [6] [7]. The seeds of single seed decent T1-7 family RNAi plants of the sixth generation were transferred to the USDA-ARS laboratory at Mississippi State, Mississippi, USA to evaluate RNAi plant performance under the USA environments. Comparative phenotypic evaluations of US-grown RNAi and Coker 312 plants were conducted for various morphological and agronomic traits including fiber quality properties.

Seeds of individually selected PCR-positive (containing the RNAi construct) T6-7 RNAi homozygousplants were grown in the field at the North Farm R. R. Foil Plant Science Research Center of Mississippi State University. Flowers were tagged on the day of anthesis (0 DPA). Cotton bolls (10 DPA) were harvested with three biological replications on August 10, 2015 from 9 - 10 am. Fibers were carefully dissected from cotton bolls, immediately frozen in liquid nitrogen, and then stored at $-80^{\circ} \mathrm{C}$ for RNA extraction.

\subsection{RNA-Seq Library Construction and Illumina Sequencing}

Total RNA was isolated from 10 DPA fibers using a modified hot borate method [16]. Genomic DNA contamination in the RNA samples was removed with DNase I (Promega, Madison, WI, USA). Briefly, 10 - $50 \mu \mathrm{g}$ of total RNA were treated with 5 units of DNase $\mathrm{I}$ at $37^{\circ} \mathrm{C}$ for $20 \mathrm{~min}$ in a $50 \mu \mathrm{l}$ reaction according to the manufacturer's instructions. After DNase treatment, the RNA sample was cleaned up with a Qiagen RNasey Mini Kit (Qiagen, Valencia, CA, USA). The quality of the RNA sample was pre-checked on a $1 \%-1.2 \%$ agarose gel by electrophoresis, and the RNA concentration was determined with Nanodrop 2000c and a Qubit ${ }^{\circledast}$ fluorometer by using a Qubit RNA BR Assay Kit (Invitrogen, Carlsbad, CA, USA). The quality of total RNA was finally estimated using the Bioanalyzer 2100 system (Agilent Technologies, Santa Clara, CA, USA).

Two $\mu \mathrm{g}$ of total RNA with three biological replicates per genotype were used to construct RNA-Seq libraries using the TruSeq Stranded mRNA Library Prep Kit (Illumina, San Diego, CA) according to the manufacturer's instructions. All 6 RNA-Seq libraries were independently barcoded with 6 compatible TruSeq RNA indexes (Illumina, San Diego, CA, USA) for multiplexing. The size of each library was analyzed with Bioanalyzer DNA 1000 Kit (Agilent Technologies, Santa Clara, CA, USA), and the concentration of each library was quantified with the Qubit dsDNA HS Assay Kit (Thermo Fisher Scientific, Waltham, MA, USA) and qPCR assays. Based on the results from qPCR assays, all libraries were diluted to the concentration of $20 \mathrm{nM}$ and further pooled together with equal volume from each library. The pooled library sample was sequentially subjected to HiSeq 2500 system with pair-ended 50 bp $(2 \times 50)$ sequencing (Illumina, San Diego, CA, USA) for the transcriptomic analysis.

\subsection{Data Processing and Analysis}

FastQC (http://www.bioinformatics.babraham.ac.uk/projects/fastqc/) was used to 
test data quality. Trimmomatic [17] was used to trim the low-quality reads and adaptor sequences. Gossypium hirsutum L. acc. TM-1 genome [18] was used as reference for short reads mapping. ArrayStar (Version 12, DNASTAR Inc., Madison, WI, USA) was used for RNA-Seq analysis. The expression of genes was normalized by the Reads Per Kilobase of transcript per Million mapped reads (RPKM) method [19]. Blast2GO [20] and InterProScan 5 [21] were used for identifying orthologous genes and adding additional GO terms, if necessary. GO terms were mapped to the GO-slim [22] to get a broad functional overview of the transcriptome. The Fisher's exact test method [23] was used for gene set enrichment analysis [24] [25]. KEGG database [26] was used for additional protein function analysis. The mRNA sequencing data of Coker 312 and PHYA1 line were deposited into NCBI with accession numbers SRP099141 and SRP099143, respectively.

\subsection{Quantitative RT-PCR}

Total RNA of 10-DPA fiber was used as template for first-strand cDNA synthesis using M-MLV reverse transcriptase (Promega, Madison, WI, USA) according to the manufacturer's instructions. The qRT-PCR reaction was carried out on lightcycler 480 (Roche, Basel, Switzerland) with the following cycling profile: $95^{\circ} \mathrm{C}$ for $5 \mathrm{~min}$, following by 45 cycles of $10 \mathrm{sec}$ at $95^{\circ} \mathrm{C}, 15 \mathrm{sec}$ at $60^{\circ} \mathrm{C}$ and 15 sec at $72^{\circ} \mathrm{C}$. Each qRT-PCR reaction mixture contained $10 \mu \mathrm{l}$ of SYBR Green I Master (Roche, Basel, Switzerland), $1 \mu \mathrm{l}$ of forward primer $(10 \mu \mathrm{M}), 1 \mu \mathrm{l}$ of reverse primer $(10 \mu \mathrm{M}), 2 \mu \mathrm{l}$ of cDNA ( $4 \times$ fold dilution), and $6 \mu \mathrm{l}$ of $\mathrm{ddH}_{2} \mathrm{O}$. The transcript of cotton Ubiquitin 7 gene (GhUBQ7) was used to normalize the expression levels of RT-PCR products [27]. All reactions were performed with three replicates. The $2^{-\Delta \Delta \mathrm{Ct}}$ method $[\Delta \mathrm{Ct}=\mathrm{Ct}$ (differentially expressed gene) $-\mathrm{Ct}$ (UBQ7), $\Delta \Delta \mathrm{Ct}=\Delta \mathrm{Ct}(\mathrm{RNAi})-\Delta \mathrm{Ct}$ (Coker 312), $2^{-\Delta \Delta \mathrm{Ct}}=$ Relative Expression] was used to calculate relative expression of differentially expressed genes [28]. All primers were designed by using the IDT online tool (https://www.idtdna.com/scitools/Applications/RealTimePCR/).

\section{Results}

\subsection{Sequence Statistics of Six 10-DPA Fiber Libraries}

The preliminary results from 2015-2016 USA field evaluations in replicated plots suggested significant differences in fiber properties between the RNAi and Coker 312. The RNAi line in average had fiber length of 1.21 inch and strength of 31.8 gm/tex versus Coker 312 control with fiber length of 1.16 inch and strength of $29.4 \mathrm{gm} /$ tex (Jenkins et al. 2017; unpublished results). To determine global transcriptome differences in elongated fibers between PHYA1 RNAi and Coker 312 lines, the 10-DPA fiber RNA samples from three individual plants of each line were used to generate 6 independent libraries that were subsequently sequenced using the Illumina HiSeq 2500 sequencing platform. Approximately 565.8 million reads of 50-bp long were generated from all 6 libraries (Table 1). Low quality 
Table 1. Total reads statistics of RNA-Seq libraries.

\begin{tabular}{ccccccc}
\hline \multirow{2}{*}{ Sample } & \multicolumn{3}{c}{ Coker 312 } & \multicolumn{3}{c}{ RNAi } \\
\cline { 2 - 7 } & CF 1 & CF 2 & CF 3 & RF 1 & RF 2 & RF 3 \\
\hline Total Sample Reads & $94,720,967$ & $93,523,005$ & $94,121,986$ & $95,064,738$ & $94,462,679$ & $93,860,621$ \\
Total Reads Mapped & $94,694,073$ & $92,987,578$ & $93,840,825$ & $94,718,530$ & $94,205,949$ & $93,693,368$ \\
Total Unque Reads & $28,996,162$ & $27,493,684$ & $28,244,922$ & $28,662,405$ & $27,759,879$ & $26,857,354$ \\
\hline
\end{tabular}

Note: CF and RF denote the fibers from Coker 312 and $P H Y A 1$ RNAi plants, respectively. The RNA samples from Coker 312 and PHYA1 RNAi lines have 3 biological replicates (replicates 1 - 3).

reads and adaptor sequences were then trimmed off with Trimmomatic [17] and the clean reads were mapped to 70,478 transcripts from the Gossypium hirsutum L. acc. TM-1 genome sequence [18].

\subsection{Global Transcriptome Changes in PHYA1 RNAi Plant Fiber Development}

The mapped sequenced reads of all identified transcripts were used for differential expression analysis with the ArrayStar program with a FDR less than 0.05. The overall expression patterns of the mapped genes between the RNAi line and Coker 312 were similar with a linear correlation $\mathrm{R}^{2}=0.9747$ (Figure 1). A total of 142 genes (fold change $\geq 2$ ) were either up or down regulated in PHYA1 RNAi plant compared to Coker 312. Of these genes, 138 genes were down-regulated and 4 genes were up-regulated. The 142 genes differentially expressed in $P H Y A 1$ 10-DPA fibers were listed in Table 2. RNA-Seq data showed high levels of transcripts of $P H Y A 1$ sequence tags in RNAi line compared to wild-type Coker 312, which was due to the transcription of the hinge region (213 bp) of the PHYA1 gene in the RNAi hairpin construct under the strong constitutive CaMV 35S promoter. Because extremely low counts of RNA-seq tags (below 10) were mapped to the PHYA1 coding region after filtering data from the hinge region, it was not feasible to use statistical tools to determine whether there was a difference in PHYA1 expression between RNAi and Coker 312 lines. Our qRT-PCR results also indicated that $P H Y A 1$ was expressed at very low levels in fiber, and no significant difference in PHYA1 transcript levels was observed between the two lines in 10-DPA fibers (data not shown).

The transcript levels of many transcription factor families were significantly changed. For example, 11 genes in the WRKY gene family (Gh_D08G1232, Gh_A08G2417, Gh_D04G1318, Gh_A03G0210, Gh_D05G0600, Gh_D06G1078, Gh_D03G1371, Gh_A06G1923, Gh_A05G0483, Gh_A06G0917 and Gh_A07G0-017) encoding WRKY transcription factors or like proteins were down-regulated in 10-DPA fibers of the PHYA1 RNAi line compared to Coker 312. The WRKY gene family had been revealed to participate in multiple fiber developmental processes [29]. Two genes encoding ABA 8'-hydroxylase (Gh_A08G1344 and Gh_D08G1639), a type of cytochrome P450 monooxygenase, in catalyzing the first step in oxidative degradation of ABA were down-regulated [30] [31]. ABA 


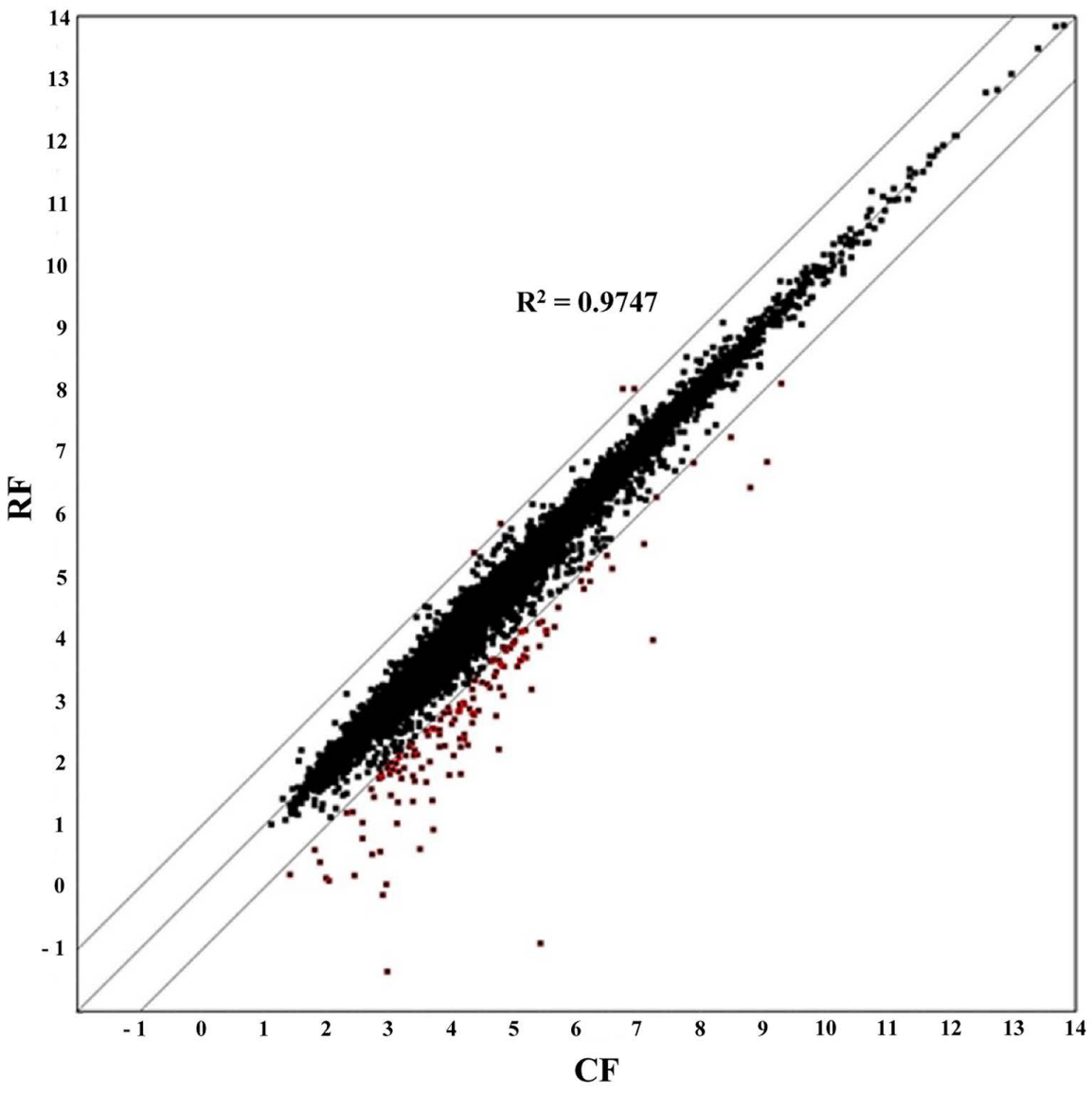

Figure 1. Transcriptome scatter plot of $P H Y A 1$ RNAi plant (RF) compared to Coker 312 (CF). Red data points indicate genes that show $\geq 2$-fold changes in expression with a FDR adjusted $\mathrm{p} \leq 0.05, \mathrm{R}^{2}=0.9747$.

was reported to play a negative role in fiber development [11]. Certain proteins and enzymes which are involved in cell wall biogenesis and organization process were also affected by silencing the $P H Y A 1$ gene. For example, the expression of 4 genes encoding xyloglucan endotransglucosylase hydrolase family protein (Gh_D02G0992, Gh_A05G2724, Gh_D05G3030 and Gh_A05G3992) and the gene Gh_A11G0519 for udp-glucuronate:xylan alpha-glucuronosyltransferase 1-like, a cell wall-modifying enzyme, were down-regulated. In addition, sucrose synthases (Gh_A08G1031 and Gh_D08G1309) and proteins including linoleate 13s-lipoxygenase (Gh_A10G0504) and non-specific lipid transfer protein (Gh_A09G1902) related to lipid metabolism were also affected.

These differentially expressed genes (DEGs) were distributed across all 26 chromosomes in the tetraploid progenitor A-genome and D-genome (Figure 2). Of these 142 genes, 68 genes were originated from A-genome, and 71 genes were from D-genome. In A-genome, the DEGs were most abundantly located in chromosome 5 with 12 genes, which had $18 \%$ of the DEGs distributed in A-genome. Following the chromosome 5 was the chromosome 8 with 10 DEGs, composed of $15 \%$ of the group. For D-genome, similar distribution patterns were found; chromosomes 19 and 24 had the highest numbers of DEGs, but chromosome 
Table 2. The list of 142 differentially expressed genes (fold change $\geq 2$ ) in $P H Y A 1$ RNAi line.

\begin{tabular}{|c|c|c|}
\hline Gene Accession Number (NBI) & Gene Annotation & Fold Change \\
\hline Gh_D01G0906 & phosphoprotein ecpp 44-like & 0.0125 \\
\hline Gh_D08G1232 & probable wrky transcription factor 41 & 0.05 \\
\hline Gh_A05G1317 & pyruvate decarboxylase 1 & 0.1048 \\
\hline Gh_D10G2595 & ---NA--- & 0.1233 \\
\hline Gh_A08G2417 & probable wrky transcription factor 41 & 0.133 \\
\hline Gh_D04G1318 & probable wrky transcription factor 33 & 0.1359 \\
\hline Gh_D02G0992 & $\begin{array}{l}\text { xyloglucan endotransglucosylase hydrolase } \\
\text { family protein }\end{array}$ & 0.1463 \\
\hline Gh_D04G1245 & bahd acyltransferase dcr & 0.1735 \\
\hline Gh_D02G0733 & alcohol dehydrogenase & 0.1948 \\
\hline Gh_D07G1319 & $\begin{array}{l}\text { uncharacterized calcium-binding protein } \\
\text { at } \lg 02270 \text {-like isoform } \times 1\end{array}$ & 0.1988 \\
\hline Gh_D08G1639 & abscisic acid 8-hydroxylase 1-like & 0.2031 \\
\hline Gh_D12G1525 & lov domain-containing protein & 0.2059 \\
\hline Gh_D05G3509 & scarecrow-like protein 21 & 0.2105 \\
\hline Gh_A02G0689 & alcohol dehydrogenase & 0.2159 \\
\hline Gh_A05G0931 & probable protein phosphatase 2 c 25 & 0.218 \\
\hline Gh_D08G2557 & phosphatase $2 \mathrm{c}$ family isoform 1 & 0.2244 \\
\hline Gh_A08G1344 & abscisic acid 8-hydroxylase 1-like & 0.233 \\
\hline Gh_D02G0732 & alcohol dehydrogenase class-p-like & 0.2338 \\
\hline Gh_D09G0953 & probable ccr4-associated factor 1 homolog 11 & 0.2504 \\
\hline Gh_D05G0148 & ein3-binding f-box protein 1-like & 0.2542 \\
\hline Gh_D08G2556 & nuclease harbil & 0.2573 \\
\hline Gh_A05G0839 & exocyst complex component exo70b1-like & 0.2622 \\
\hline Gh_A08G2389 & oxalate--ligase & 0.265 \\
\hline Gh_D04G0293 & nac domain-containing protein 2 -like & 0.2686 \\
\hline Gh_A09G0923 & probable ccr4-associated factor 1 homolog 11 & 0.271 \\
\hline Gh_A05G2138 & serine threonine-protein kinase-like protein ccr4 & 0.28 \\
\hline Gh_D06G1403 & ethylene-responsive transcription factor 4-like & 0.2846 \\
\hline Gh_D07G0283 & $\begin{array}{l}\text { PREDICTED: uncharacterized protein } \\
\text { LOC105769700 }\end{array}$ & 0.2886 \\
\hline Gh_A10G0504 & linoleate 13s-lipoxygenase 3-chloroplastic & 0.2941 \\
\hline Gh_A08G0965 & nadp-specific glutamate & 0.2982 \\
\hline Gh_D05G3030 & $\begin{array}{l}\text { xyloglucan endotransglucosylase hydrolase } \\
\text { family protein }\end{array}$ & 0.299 \\
\hline
\end{tabular}




\section{Continue}

\begin{tabular}{|c|c|c|}
\hline Gh_D06G1513 & endoplasmic reticulum oxidoreductin-1-like & 0.3001 \\
\hline Gh_D08G2484 & ein3-binding f-box protein 1-like & 0.3076 \\
\hline Gh_D02G1480 & probable ribose-5-phosphate isomerase 2 & 0.31 \\
\hline Gh_A05G2724 & $\begin{array}{l}\text { xyloglucan endotransglucosylase hydrolase } \\
\text { family protein }\end{array}$ & 0.3247 \\
\hline Gh_A08G2191 & nuclease harbil & 0.3272 \\
\hline Gh_D07G2014 & nam protein & 0.33 \\
\hline Gh_A08G2112 & ein3-binding f-box protein 1-like & 0.3311 \\
\hline Gh_A07G1811 & nam protein & 0.3327 \\
\hline Gh_D01G1679 & ---NA--- & 0.3346 \\
\hline Gh_D05G1208 & tetratricopeptide repeat-like superfamily & 0.3389 \\
\hline Gh_D08G1346 & protein rolling stone-like isoform $\times 2$ & 0.3394 \\
\hline Gh_D03G1189 & scarecrow-like protein 34 & 0.3401 \\
\hline Gh_A03G0210 & probable wrky transcription factor 25 & 0.3409 \\
\hline Gh_A13G1709 & nuclease harbil & 0.346 \\
\hline Gh_D01G1033 & zinc finger protein zat10-like & 0.3467 \\
\hline Gh_D10G2455 & $\begin{array}{l}\text { zinc finger ccch domain-containing protein } \\
\text { 29-like }\end{array}$ & 0.3469 \\
\hline Gh_A03G2061 & protein yls9-like & 0.3497 \\
\hline Gh_D05G0600 & wrky transcription factor 40 -like protein & 0.3524 \\
\hline Gh_A03G0889 & phosphate transporter pho1 homolog 3-like & 0.3552 \\
\hline Gh_D08G0665 & auxin-induced protein $22 \mathrm{~b}$ & 0.3636 \\
\hline Gh_D12G0236 & maternal effect embryo arrest 14 isoform 1 & 0.3643 \\
\hline Gh_A10G1443 & protein srg 1 & 0.3655 \\
\hline Gh_D01G0450 & ethylene-responsive transcription factor 4-like & 0.3663 \\
\hline Gh_D02G0832 & $\begin{array}{l}\text { ethylene-responsive transcription factor } \\
\text { rap2-4-like }\end{array}$ & 0.3667 \\
\hline Gh_A09G1902 & non-specific lipid-transfer protein at2g13820 & 0.3691 \\
\hline Gh_D02G0417 & ethylene receptor 2 & 0.3707 \\
\hline Gh_A03G2168 & ---NA--- & 0.3749 \\
\hline Gh_Sca006021G02 & calcium-dependent lipid-binding family & 0.3758 \\
\hline Gh_A04G0305 & ethylene-responsive transcription factor 4-like & 0.381 \\
\hline Gh_A08G1031 & sucrose synthase 1 & 0.3839 \\
\hline Gh_A06G1144 & ethylene-responsive transcription factor 4-like & 0.389 \\
\hline Gh_A10G2134 & $\begin{array}{l}\text { zinc finger ccch domain-containing protein } \\
\text { 29-like }\end{array}$ & 0.39 \\
\hline Gh_D06G1078 & wrky transcription factor 40 -like protein & 0.3922 \\
\hline
\end{tabular}




\section{Continue}

\begin{tabular}{|c|c|c|}
\hline Gh_D03G1371 & probable wrky transcription factor 25 & 0.3947 \\
\hline Gh_A02G0671 & u-box domain-containing protein 28 -like & 0.3974 \\
\hline Gh_D12G0679 & maternal effect embryo arrest isoform partial & 0.4007 \\
\hline Gh_A07G0226 & hypothetical protein F383_30923 & 0.4008 \\
\hline Gh_A12G2296 & heavy metal-associated domain protein & 0.4038 \\
\hline Gh_A11G1993 & probable indole-3-acetic acid-amido synthetase & 0.4044 \\
\hline Gh_A01G0875 & prolyl endopeptidase & 0.4047 \\
\hline Gh_D08G2140 & probable protein phosphatase 2 c 25 & 0.4066 \\
\hline Gh_A12G0132 & nitronate monooxygenase & 0.4074 \\
\hline Gh_A10G0255 & ethylene-responsive transcription factor 4 -like & 0.408 \\
\hline Gh_D02G1817 & ---NA--- & 0.4085 \\
\hline Gh_D06G0817 & $\begin{array}{l}\text { ethylene-responsive transcription factor } \\
\text { erf017-like }\end{array}$ & 0.4092 \\
\hline Gh_A05G0434 & ein3-binding f-box protein 1 & 0.4098 \\
\hline Gh_A06G1910 & nac domain-containing protein 2 & 0.4106 \\
\hline Gh_D03G1188 & scarecrow-like protein 30 & 0.411 \\
\hline Gh_A03G1618 & probable protein phosphatase $2 \mathrm{c} 63$ & 0.4134 \\
\hline Gh_A05G3992 & $\begin{array}{l}\text { xyloglucan endotransglucosylase hydrolase } \\
\text { family protein }\end{array}$ & 0.4146 \\
\hline Gh_A06G1923 & probable wrky transcription factor 40 & 0.4189 \\
\hline Gh_D08G1949 & 4-coumarate--ligase-like 10 & 0.423 \\
\hline Gh_A09G0534 & stem-specific protein tsjt1 & 0.4249 \\
\hline Gh_A05G0483 & wrky transcription factor 40 -like protein & 0.4298 \\
\hline Gh_Sca013634G01 & $\begin{array}{l}\text { two-component response regulator-like aprr5 } \\
\text { isoform } \times 2\end{array}$ & 0.4309 \\
\hline Gh_D05G3348 & ethylene-responsive transcription factor 4-like & 0.4321 \\
\hline Gh_D11G3494 & disease resistance protein $\mathrm{rga} 4$ isoform $\times 1$ & 0.4323 \\
\hline Gh_A12G1612 & disease resistance protein rga3 & 0.4323 \\
\hline Gh_A05G2211 & respiratory burst oxidase homolog protein d-like & 0.4323 \\
\hline Gh_A11G0519 & $\begin{array}{l}\text { udp-glucuronate: xylan } \\
\text { alpha-glucuronosyltransferase 1-like }\end{array}$ & 0.436 \\
\hline Gh_D02G2032 & probable protein phosphatase $2 \mathrm{c} 63$ & 0.4368 \\
\hline Gh_A01G1439 & expansin-like a2 & 0.4384 \\
\hline Gh_D10G1768 & acetate butyrate--ligase peroxisomal-like & 0.4392 \\
\hline Gh_A03G1070 & probable ribose-5-phosphate isomerase 2 & 0.4397 \\
\hline Gh_A01G1726 & protein yls9-like & 0.4404 \\
\hline Gh_D07G1307 & suppressor of disruption of tfiis & 0.4435 \\
\hline
\end{tabular}




\section{Continue}

\begin{tabular}{|c|c|c|}
\hline Gh_D13G0440 & classical arabinogalactan protein 9 & 0.4437 \\
\hline Gh_A04G0196 & scarecrow-like protein 21 & 0.4467 \\
\hline Gh_A06G0917 & wrky transcription factor 40 -like protein & 0.4499 \\
\hline Gh_D04G1573 & glutamyl-trna amidotransferase subunit a & 0.4514 \\
\hline Gh_A05G1814 & lob domain-containing protein 39 -like & 0.4515 \\
\hline Gh_A05G3754 & wat1-related protein at4g08300-like & 0.452 \\
\hline Gh_A08G1791 & probable protein phosphatase 2 c 25 & 0.4529 \\
\hline Gh_D03G1808 & $\begin{array}{l}\text { late embryogenesis abundant } \\
\text { hydroxyproline-rich glycoprotein isoform } 1\end{array}$ & 0.4549 \\
\hline Gh_A13G1311 & $\begin{array}{l}\text { 9-cis-epoxycarotenoid dioxygenase } \\
\text { chloroplastic-like }\end{array}$ & 0.4563 \\
\hline Gh_D02G0837 & protein exordium-like & 0.4565 \\
\hline Gh_D06G1046 & ein3-binding f-box protein 1-like & 0.4572 \\
\hline Gh_A05G3796 & cyclin family isoform 1 & 0.4592 \\
\hline Gh_A11G0944 & $\begin{array}{l}\text { endonuclease or glycosyl hydrolase with } \\
\text { c2h2-type zinc finger isoform } 1\end{array}$ & 0.4615 \\
\hline Gh_D05G0562 & ein3-binding f-box protein 1-like & 0.4656 \\
\hline Gh_A07G1599 & $\begin{array}{l}\text { probable sodium-coupled neutral amino acid } \\
\text { transporter } 6\end{array}$ & 0.4673 \\
\hline Gh_D06G2235 & scarecrow-like protein 13 & 0.4675 \\
\hline Gh_A11G0020 & purple acid phosphatase 17 -like & 0.4688 \\
\hline Gh_A06G0709 & $\begin{array}{l}\text { ethylene-responsive transcription factor } \\
\text { erf017-like }\end{array}$ & 0.472 \\
\hline Gh_D05G1276 & inorganic pyrophosphatase 1-like & 0.475 \\
\hline Gh_D11G3015 & soybean gene regulated by cold- & 0.4753 \\
\hline Gh_D12G2716 & $\begin{array}{l}\text { two-component response regulator-like aprr5 } \\
\text { isoform xl }\end{array}$ & 0.4763 \\
\hline Gh_D02G1271 & phosphate transporter pho1 homolog 3-like & 0.4765 \\
\hline Gh_A10G1517 & acetate butyrate--ligase peroxisomal-like & 0.4783 \\
\hline Gh_D05G2829 & gata transcription factor 8-like & 0.4803 \\
\hline Gh_A09G0414 & scarecrow-like protein 8 & 0.4814 \\
\hline Gh_A10G2086 & uncharacterized acetyltransferase at3g50280-like & 0.4815 \\
\hline Gh_A07G0017 & probable wrky transcription factor 17 & 0.4832 \\
\hline Gh_A08G0581 & $\begin{array}{l}\text { calcium-transporting atpase plasma } \\
\text { membrane-type }\end{array}$ & 0.4834 \\
\hline Gh_A03G0639 & udp-glycosyltransferase 89b1-like & 0.4841 \\
\hline Gh_A08G1509 & homeobox-leucine zipper protein hat4-like & 0.4847 \\
\hline Gh_A10G2166 & senescence associated gene & 0.4847 \\
\hline Gh_A02G1410 & phosphoenolpyruvate carboxykinase & 0.4873 \\
\hline Gh_D11G1089 & $\begin{array}{l}\text { endonuclease or glycosyl hydrolase with } \\
\text { c2h2-type zinc finger isoform } 1\end{array}$ & 0.4874 \\
\hline
\end{tabular}




\section{Continue}

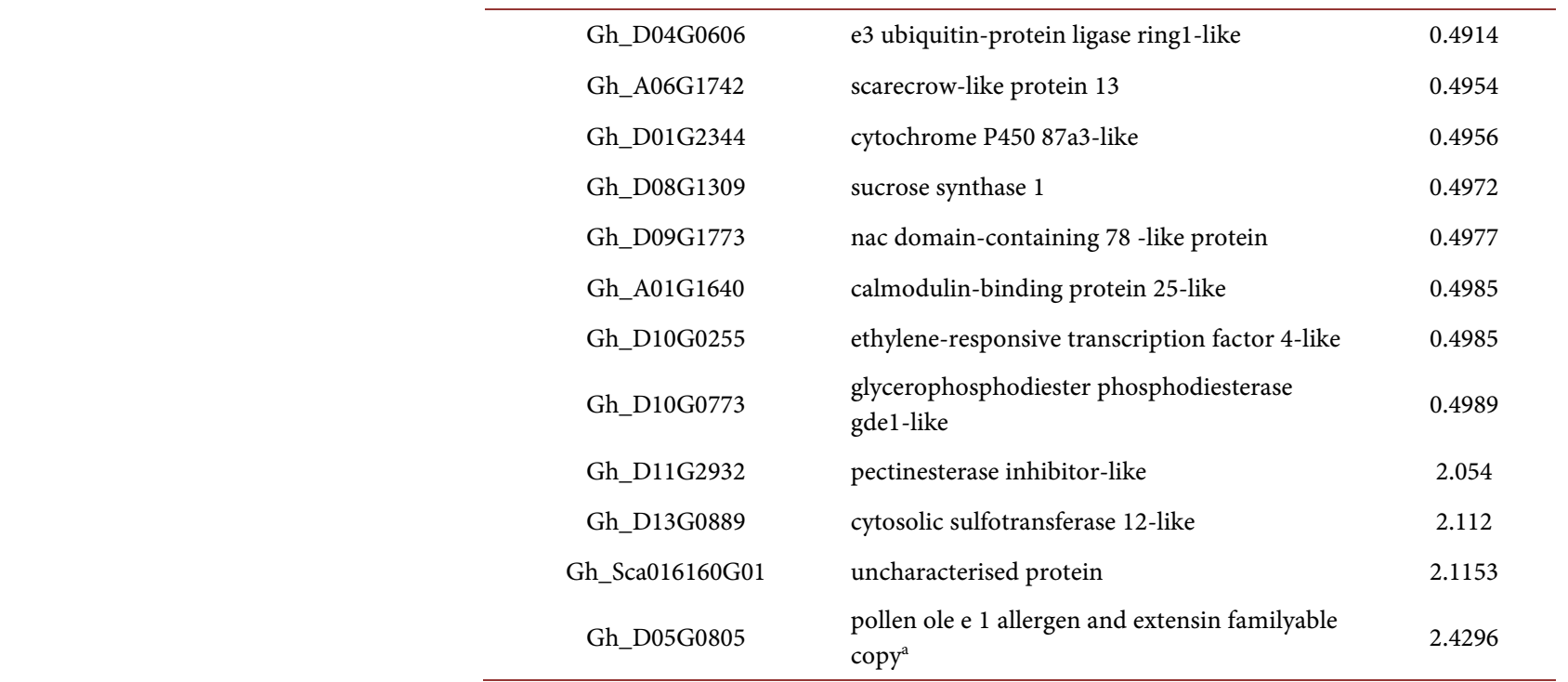
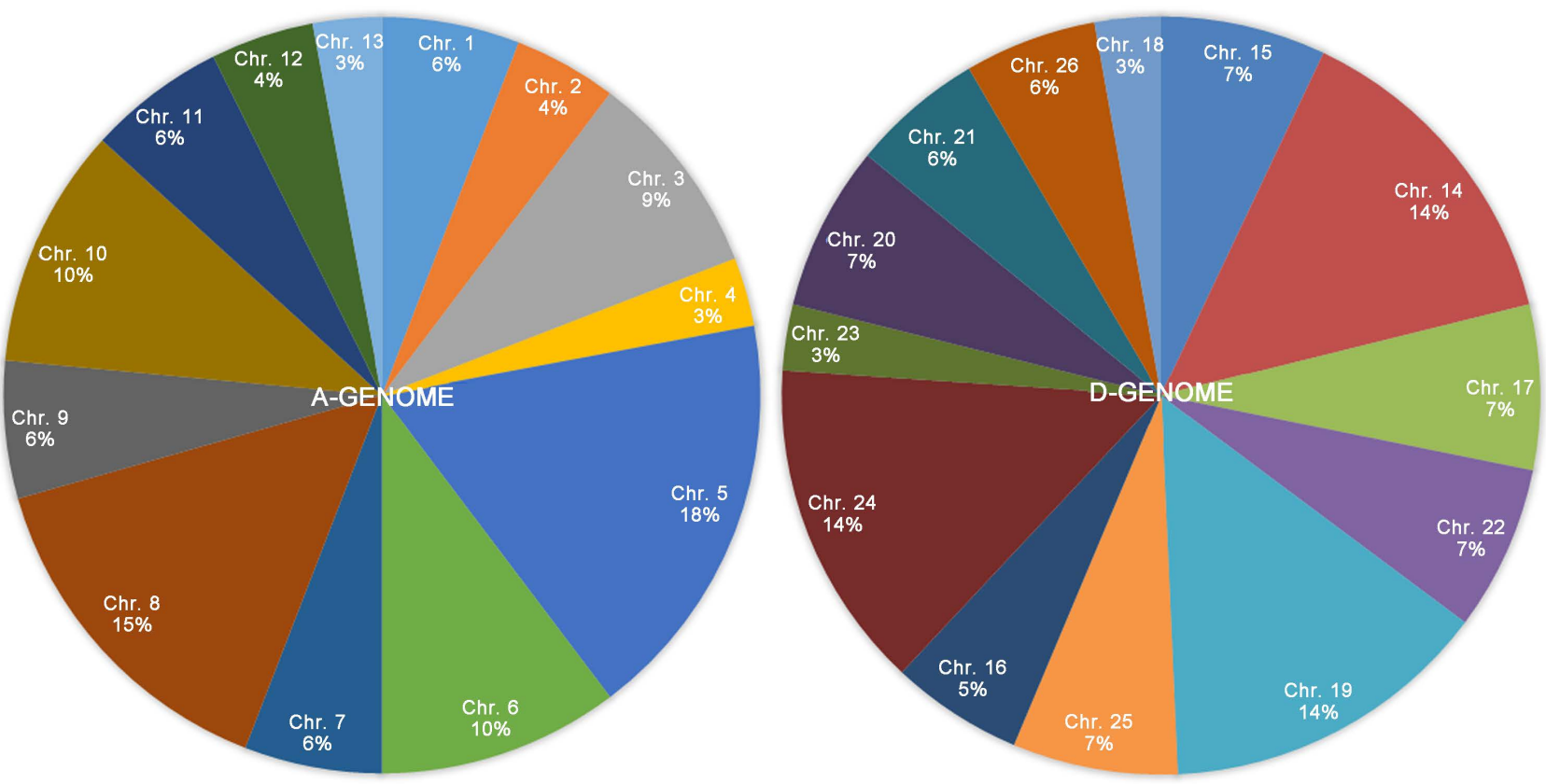

Figure 2. Chromosomal distribution of 142 differentially expressed genes. Distribution of differentially expressed transcripts was determined by the alignment of PHYA1 RNAi RNA-seq reads to the draft genome of the allotetraploid Gossypium hirsututm L. acc. TM-1.

14 also had identical numbers of DEGs as chromosomes 19 and 24. All the three chromosomes 19, 24 and 14 had 10 DEGs, each having 14\% DEGs in D-genome (Figure 2).

\subsection{Gene Annotation of DEGs}

The 142 differentially expressed genes were annotated by Blast2GO [20], and additional GO terms were added to DEGs by InterProScan 5 [21]. All the DEGs 
were subjected to GO enrichment analysis and grouped into three subsections: molecular function, biological process, and cellular components by Blast2GO (Figure 3). The results from the enrichment analysis indicated that most of the identified DEGs were involved in cellular metabolic process, heterocyclic/organic cyclic compound binding and multiple enzyme (hydrolase, transferase, and oxidoreductase) activities, and cell structures which have been reported to play important roles in fiber development (Figure 3).

\subsection{KEGG Pathway Analysis}

To identify metabolic pathways in the RNAi line during the fiber elongation stage, the 142 DEGs were mapped to KEGG database [26]. As a result, 28 pathways were mapped in the database and they were mostly related to glycolysis/gluconeogenesis, pyruvate metabolism, and metabolism by cytochrome P450 (Figure 4).

\subsection{Validation of RNA Sequencing Results by Quantitative Real-Time PCR Analysis (qRT-PCR)}

To test whether the RNA-seq gene expression results were reliable, RNA transcripts of 15 DEGs in PHYA1 RNAi plant were selected for qRT-PCR analysis

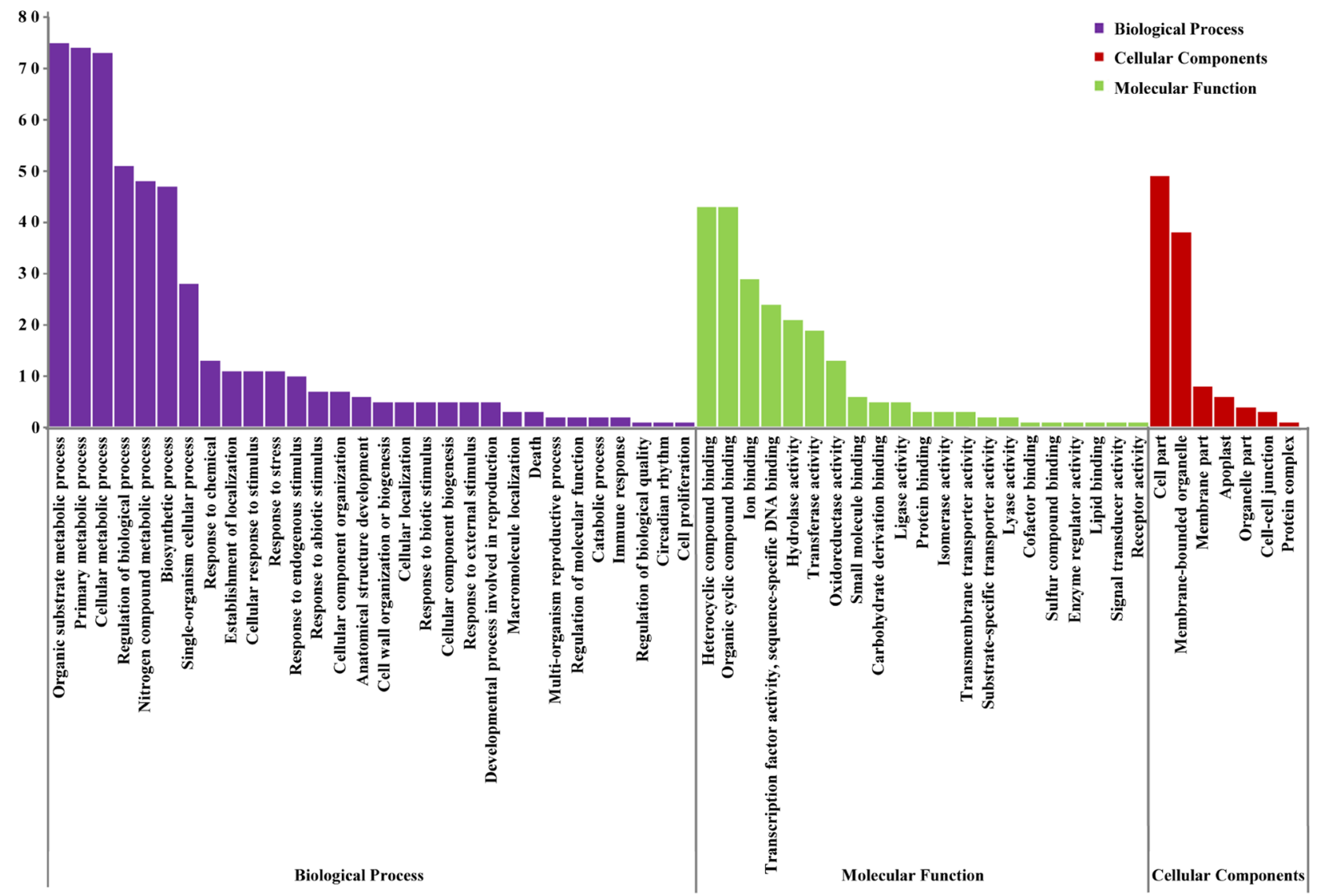

Figure 3. Gene ontology categories of differentially expressed genes (fold change $\geq 2$ ) in PHYA1 RNAi line compared to Coker 312. The number of differentially expressed genes in each category is shown in the vertical axis. 


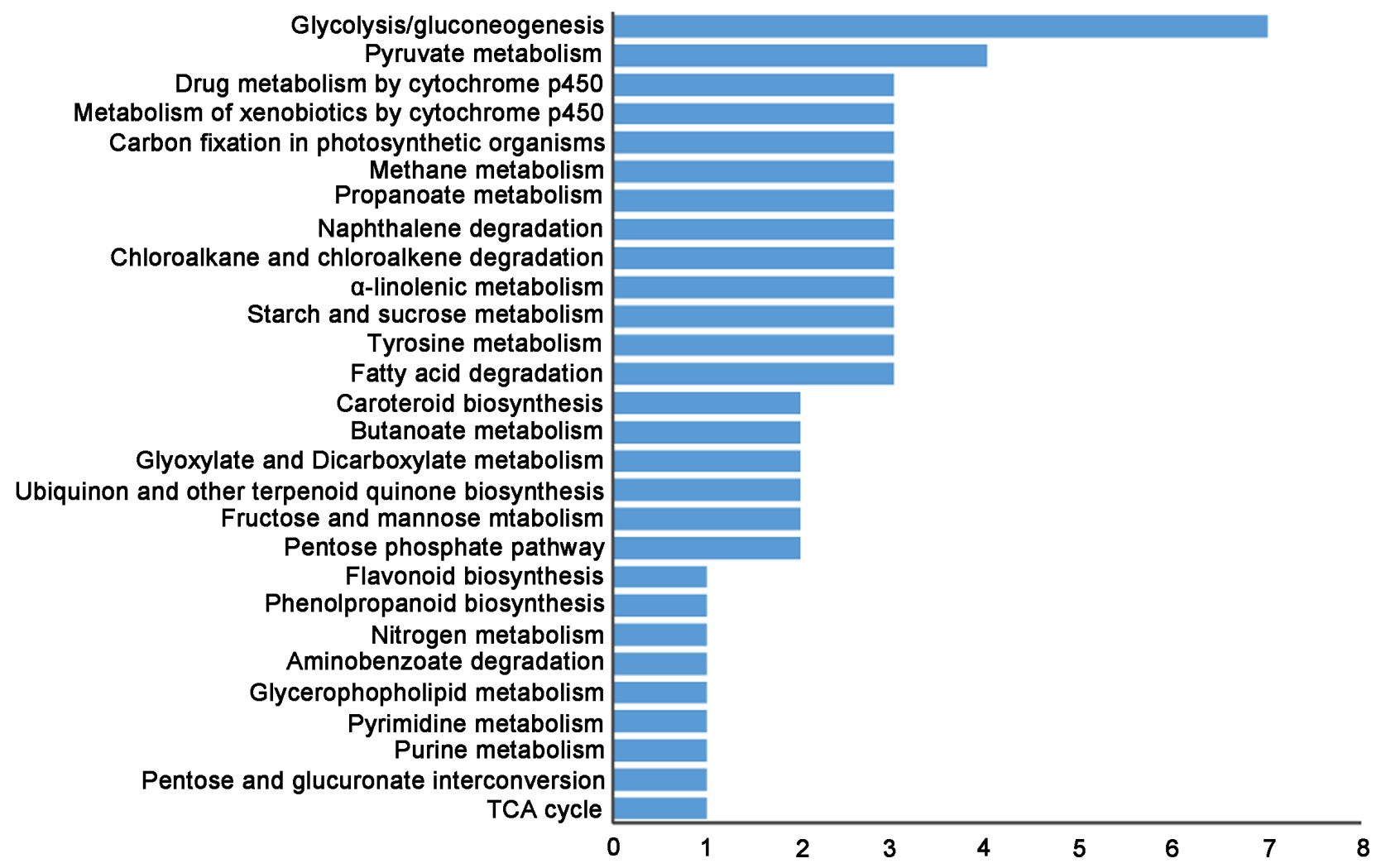

Figure 4. Kyoto encyclopedia of genes and genomes pathway classifications of differentially expressed genes. The number of differentially expressed transcripts in each pathway is shown.

(primers used for qRT-PCR are listed in Table 3). A comparison of the expression of each transcript by qRT-PCR and RNA-seq was made and shown in Figure 5. All the 15 transcripts were successfully detected by qRT-PCR, and the expression patterns of these transcripts showed general agreement with RNA-Seq results. These 15 transcripts include four up-regulated genes (Figure 5). Three out of the four genes were successfully annotated and they were pollen ole e1 allergen and extension family protein (Gh_D05G0805), cytosolic sulfotransferase 12-like protein (Gh_D13G0889), and pectinesterase inhibitor-like protein (Gh_D11G2932). The gene with the accession number Gh_Sca016160G01 was uncharacterized (Table 2).The rest of the 11 genes were down-regulated, and four of them had more than 8-fold down-regulation in RNAi plants. The expression levels of three out of the four genes were consistent with the results from RNA-seq, and they encoded WRKY transcription factor 41 (Gh_D08G1232), pyruvate decarboxylase 1 (Gh_A05G1317), and an unknown gene (Gh_D10G2595). A phosphoprotein ecpp44-like protein (Gh_D01G0906) gene was about 80-fold down-regulated in RNAi plants via RNA sequencing, however, it only showed approximately 4-fold down-regulation by the qRT-PCR method (Table 2 and Figure 5). This discrepancy between RNA-seq and qRT-PCR results could have been caused by very low counts of transcripts detected in the RNAi line, which were usually unreliable for down-stream analysis. The other seven genes include Gh_D09G0953 (probable ccr4-associated factor 1 homolog 11), Gh_D05G3509 
Table 3. Primers used for quantitative RT-PCR.

\begin{tabular}{|c|c|}
\hline Primer name & Primer sequences $\left(5^{\prime} \rightarrow 3\right)$ \\
\hline Gh_D01G0906F & GCGAGGGATGTTTGATTTCTTG \\
\hline Gh_D01G0906R & CCAGGAGACTGTGTTTCTTCTC \\
\hline Gh_D08G1232F & TGTGCCAGAGTCTCCTCTAA \\
\hline Gh_D08G1232R & CCACCTAGGCATCATCTTTCTC \\
\hline Gh_A05G1317F & GAAAGCAAGCCCGTTTACATTAG \\
\hline Gh_A05G1317R & TACCTTTGGAGCGAGAAAGAAG \\
\hline Gh_D10G2595F & CCATAACCGCGACCTTAACT \\
\hline Gh_D10G2595R & CGGCAACTTCTTCACTGTTTC \\
\hline Gh_D02G0992F & TCGAGTTCCTCGGGAATTTAAG \\
\hline Gh_D02G0992R & CAGTTGGGTCAAACCAGAGATA \\
\hline Gh_D02G0733F & GCAGAAGGATGAAGTCCGTATTA \\
\hline Gh_D02G0733R & GACCTAGTATGCGAGGAAACAG \\
\hline Gh_D08G1639F & GGTGTCCCTGTGTGATGATT \\
\hline Gh_D08G1639R & TGCCCAACATCСТСТСТTTAC \\
\hline Gh_D05G3509F & GAGGTCCTTATGTGCGGATTAC \\
\hline Gh_D05G3509R & CTGCTCGGATAGTTCCATCAAA \\
\hline Gh_A05G0931F & TCCGTCCGGGTCTCTATTATC \\
\hline Gh_A05G0931R & TTGGCСTCTTCСТCTTCAATATC \\
\hline Gh_D09G0953F & GAGGAGGCAAGGGATTGATTT \\
\hline Gh_D09G0953R & CCСAACTCACCGACTCATTAC \\
\hline Gh_D05G0148F & CTCCTGTGCTTGTGTCTCTAAG \\
\hline Gh_D05G0148R & CGTTCTCCTTGACCACCTTT \\
\hline Gh_D11G2932F & CTTTGGCACTTCACGAACAAG \\
\hline Gh_D11G2932R & AACTCACGCCTCTGGTAAAC \\
\hline Gh_D13G0889F & CTTTGGCACTTCACGAACAAG \\
\hline Gh_D13G0889R & AACTCACGCCTCTGGTAAAC \\
\hline Gh_Sca016160G01F & AGTGCTTTACAACCCGAAGG \\
\hline Gh_Sca016160G01R & ACACGGTCCAGACTCCTAC \\
\hline Gh_D05G0805F & GTGGACCAAACCAGCTATACA \\
\hline Gh_D05G0805R & AGGGCATGAAGTGGAGAAAG \\
\hline Gh_UBQ7F & GAAGGCATTCCACCTGACCAAC \\
\hline Gh_UBQ7R & CTTGACCTTCTTCTTCTTGTGCTTG \\
\hline
\end{tabular}

(scarecrow-like protein 21), Gh_D05G0148 (ein3-binding f-box protein 1-like), Gh_D08G1639 (abscisic acid 8'-hydroxylase 1-like), Gh_A05G0931 (probable protein phosphatase 2c 25), Gh_D02G0733 (alcohol dehydrogenase), and Gh_D02G0992 (xyloglucan endotransglucosylase hydrolase family protein) were all down-regulated in the RNAi line, which were consistent with the results 


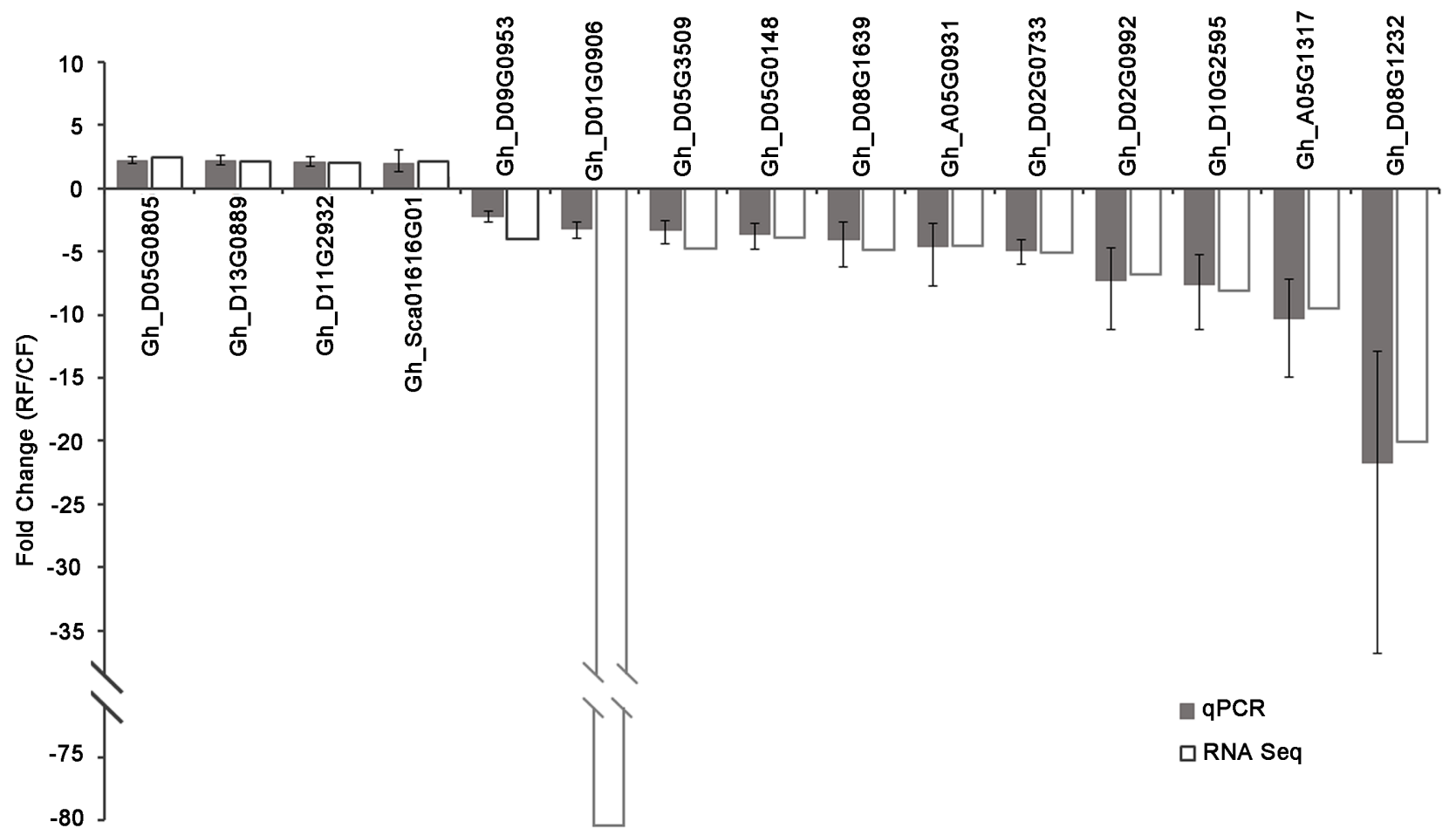

Figure 5. Validation of the expression patterns of differentially expressed genes in 10 DPA fiber of $P H Y A 1$ RNAi line by qRT-PCR. Gene expression was represented as relative fold change $2^{-\Delta \Delta C T}\left(\Delta \Delta C_{T}=\Delta C_{T} R N A i-\Delta C_{T}\right.$ Coker 312). The expression levels of genes were normalized by using GhUBQ7 as a reference. Three biological replicates and three technical replicates were included for qRT-PCR experiments. The error bar represents the confidence limits.

from RNA-Seq (Table 2 and Figure 5). In summary, the majority (except for Gh_D01G0906) of the selected transcripts tested by qRT-PCR showed similar expression patterns as determined by the statistical analysis of RNA-Seq data.

\section{Discussion}

\subsection{Transcriptome Profiling of 10-DPA Fibers in RNAi and Coker 312 Lines}

The PHYA1 RNAi cotton was reported to have a 5\% increase in fiber length compared to non-transformed Coker 312 [6]. The field evaluation of RNAi cotton plants grown in the USA environment in 2015-2016 also showed that the RNAi line had longer fiber than that of Coker 312 (Jenkins et al. 2017; unpublished results). The fiber length is generated through primary wall synthesis which dominates in 10-DPA fiber. Although the components of fiber cell wall change dynamically throughout the development, the primary walls of 10-DPA cotton fibers, similar to other expanding plant cells, mainly contain cellulose, pectin, xyloglucan, lignin and hydroxyproline-rich glycoprotein [32]. Extensin, one of the glycoproteins, is involved in the generation of scaffolding network of the cell wall [33]. In this study, a pollen ole e 1 allergen and extensin protein encoded by the gene Gh_D05G0805, was highly enriched in 10-DPA RNAi cotton 
(Table 2 and Figure 5). The ole e 1 containing proteins were first identified as major allergens and present commonly in many plants, including cotton [34]. It was expressed not only in pollen but also in other plant tissues [35] [36] [37]. An ole e 1 containing protein encoded by AtAGP30 in Arabidopsis was shown to be required for root regeneration and seed germination [37]. It is reasonable to propose that extensin plays an essential role in primary cell wall architecture of cotton fiber just as in other plant cells.

It is tempting to speculate on the relationship of molecular changes associated with the cotton PHYA1 RNAi phenotypes based on the results of altered molecular processes in the fiber of RNAi plants. Shifting from vegetative growth to reproductive growth, establishment of the seedling, and switching of the circadian clock are regulated by phytochrome [38] [39]. It was reported that PHYA plays an important role in seed germination under a broad spectrum of light and promoting flower under long day light condition in Arabidopsis [39]. A recent study showed that transgenic cotton plants ( $G$. hirsutum) overexpressed the phytochrome B gene from Arabidopsis thaliana had increased plant growth and yield [38]. A previous report on biochemically purified Arabidopsis PHYA holoproteins had showed that the phytochrome molecule consisted of two structural domains connected via a flexible hinge region [39]. Recent studies on molecular mapping of fiber QTLs using the PHYA1 CAPS (cleaved amplified polymorphic sequences) marker specific to hinge region of Phytochrome A1 with flanking SSR markers reported that the PHYA1 CAPS marker was significantly linked to fiber length [15] [40]. It was found that one of the flanking markers linked to $P H Y A 1$ CAPS was associated with micronaire and lint yield in cotton [41]. These results on the indirect association of the PHYA1 CAPS marker with important fiber traits complements the results of differentially expressed genes in fiber and provide valuable information on the potential molecular basis of the cotton PHYA1 RNAi phenotypes and fiber development.

Sucrose synthase (Sus) is the major enzyme of sucrose breakdown for cellulose biosynthesis in cotton (G. hirsutum) fiber [42]. Two genes Gh_A08G1031 and Gh_D08G1309 encoding sucrose synthase 1 (Sus 1) were down-regulated in RNAi line compared to Coker 312. It was reported that the expression level of Sus 1 was low in 10 DPA fiber [43], which was perfectly consistent with the finding in this study. Although GhSus3 (U73588) has been demonstrated to play an important role in ovule development and fiber cell initiation, the functional characterization of Sus genes however was limited [43]. The development of fiber is a complex process, and there are some overlapping processes among each developmental stage. The transition from primary to secondary cell wall synthesis might occur in 10-DPA fibers. Sucrose synthase was reported to participate in secondary cell wall synthesis [44]. Therefore, the RNAi cotton line might have lagged in primary stage much longer than Coker 312, resulting in generating longer fiber. A study on the expression of Sus 1 at all developmental stages ( -3 DPA, 0 DPA, 5 DPA, 15 DPA and 20 DPA) would provide a better understanding of the function of Sus 1 in fiber development. 
In cotton, brassinosteroid (BR) positively affects fiber development [11]. It was found in this study that the gene Gh_D13G0889 encoding a cytosolic sulfotransferase 12-like protein was up-regulated, and the gene Gh_D04G1245 for a bahd acyltransferase was down-regulated in the RNAi line. The Arabidopsis brassinosteroid sulfotransferase, a type of cytosolic sulfotransferase, was found more abundant in young seedlings and actively growing cell cultures, and its expression was induced in response to salicylic acid and methyl jasmonate and bacterial pathogens [45]. The dwarfism caused by overexpression of bahd acyltransferase can be rescued by brassinosteroid in Arabidopsis [46]. In addition, acylation conjugation of brassinosteroid catalyzed by bahd acyltransferase plays a role in brassinosteroid homeostasis. Together, it suggested that fiber development might be regulated by brassinosteroid metabolism and balancing in the PHYA1 RNAi cotton.

Besides brassinosteroid, the phytohormone $\mathrm{ABA}$ is known to inhibit fiber initiation [10]. Gh_D08G1639 and Gh_A08G1344 both encoded an abscisic acid 8'-hydroxylase 1-like protein. The ABA 8'-hydroxylase catalyzed the first step of inactivation of $\mathrm{ABA}$. Therefore, the active level of $\mathrm{ABA}$ might be increased by decreasing the expression of ABA 8'-hydroxylase in the RNAi line. These results are consistent with the physiology data that $\mathrm{ABA}$ concentrations increased from the day of anthesis to 10 DPA and then declined until 20 DPA [47]. The fiber development is a dynamic process; at the stage of 10 DPA, ABA inhibits fiber cell initiation and fiber cells are predominantly elongated in RNAi cotton.

It is well known that ethylene plays a major role in cotton fiber cell elongation [48]. In this study, six genes (Gh_D05G0148, Gh_D08G2484, Gh_A08G2112, Gh_A05G0434, Gh_D05G0562 and Gh_06G1046) encoding an EIN3-binding F-box protein 1(EBF1)-like protein, were down-regulated in RNAi cotton. The reduction of EBF1 activates ethylene response by releasing EIN3 and EIL1 proteins from ubiquitination and subsequent proteasomal degradation [49]. In addition, six genes (Gh_D05G3348, Gh_D10G0255, Gh_D06G1403, Gh_D01G0450, Gh_A04G0305 and Gh_A06G1144) encoded ethylene-responsive transcription factor 4 (ERF4)-like proteins were down-regulated in the RNAi line. In Arabidopsis, AtERF4 is a negative regulator, capable of modulating ethylene and abscisic acid responses [50]. The reduction of ERF4-like proteins might promote fiber development through activating ethylene signaling pathway mediated by EIN3. Thus, ethylene signaling pathways might also contribute to fiber elongation in RNAi cotton as well as its early maturity characteristics. Additionally, many genes encoding WRKY or probable WRKY transcription factors were down-regulated in PHYA1 RNAi cotton, which was consistent with the observation of Wan et al. (2014) [51], in that WRKY family transcription factors were highly expressed in naked seed or fuzzless cotton mutants [51].

\subsection{The Possible Functions of Cytochrome P450 in Cotton Fiber Improvement}

Plant cytochrome P450s have been shown to play an important role in response 
to environmental stimuli and participate in the synthesis of a variety of biomolecules including fatty acid conjugates, plant hormones, secondary metabolites, lignin, and defensive compounds [52]. It was reported that PHYA1 RNAi plant had a better tolerance to abiotic stresses, including salinity, heat, and drought stresses with $10 \%$ - $18 \%$ yield improvement [7].

The results of KEGG analysis implied that cytochrome P450 involved pathways might play a role in fiber development in the RNAi line and explain yield improvement due to stress tolerance. In addition, a miRNAome analysis for the PHYA1 RNAi line showed that cytochrome P450 TBP (TATA Binding Proteins) have the highest hits in miRNA target prediction [53]. Cytochrome P450s were involved in almost every aspects of the plant life [54]. Based on evolutionary analyses, the oldest CYPs are involved in biosynthesis of carotenoid and sterol. The middle branches of CYPs mediate the adaptation to environment, including abiotic stresses and biotic defenses. The newest CYPs are involved in the synthesis of structural components such as lignin, fatty acid, pigments, odorants and signaling compounds [54]. Besides with improved fiber quality, PHYA1 RNAi plants have vigorous root and vegetative growth, and early flowering due to increased photosynthesis [6] [7]. CYPs are light-driven oxidase enzymes in electron transfer chains [55]. This study thus supports the hypothesis that increased photosynthesis of RNAi cotton might be via miRNA-mediated expression regulation on CYPs. In addition, CYPs are also involved in biosynthesis and catabolism of many plant hormones, such as ABA (CYP707), GA (CYP714) and BR (CYP724) [54]. ABA regulates osmotic stress tolerance [56], and GA plays a role in salinity adaptation [57]. As mentioned previously, CYPs also play crucial roles in environmental adaptation, which might explain the better tolerance of RNAi cotton to salinity, drought and heat stresses as well as increase of potential and operative yields.

\section{Conclusion}

RNA-seq based comparative transcriptome profiles of 10 DPA fiber tissues of PHYA1 RNAi lines and its wild-type genotypes not only revealed in-depth insights into the key molecular signatures and altered genetic pathways, explaining improved fiber characteristics in the genetic background of cotton $P H Y A 1$ gene interference, but also indirectly explained a better environmental adaptation, improved flowering and maturity and yield potential of RNAi lines. Results should be helpful in future fine-tuning and re-programming of fiber development through targeted engineering of characterized signatures of key genetic pathways or their combinations using new generation of genome modification and editing tools.

\section{Acknowledgements}

The authors gratefully acknowledge that this research was made possible through the cooperative research agreements between USDA/ARS and supported by Mississippi State University/Mississippi Agricultural and Forestry Experiment Sta- 
tion (MAFES). The authors gratefully acknowledge the help and support of Dr. Kater Hake, Cotton Incorporated in this research. We thank Academy of Science of Uzbekistan for sharing RNAi cotton seeds to the labs of USDA-ARS, USA and Technology Transfer Office of USDA making these seeds available for this study.

\section{References}

[1] Abdellatif, K.F., Khidr, Y., El-Mansy, Y.M., El-Lawendey, M.M. and Soliman, Y.A. (2012) Molecular Diversity of Egyptian Cotton (Gossypium barbadense L.) and Its Relation to Varietal Development. Journal of Crop Science and Biotechnology, 15, 93-99. https://doi.org/10.1007/s12892-011-0120-5

[2] Smith, C.W. and Coyle, G.G. (1997) Association of Fiber Quality Parameters and Within-Boll Yield Components in Upland Cotton. Crop Science, 37, 1775-1779. https://doi.org/10.2135/cropsci1997.0011183X003700060019x

[3] Basra, A.S. and Malik, C. (1984) Development of the Cotton Fiber. International Review of Cytology, 89, 65-113. https://doi.org/10.1016/S0074-7696(08)61300-5

[4] Seagull, R.W., Oliveri, V., Murphy, K., Binder, A. and Kothari, S. (2000) Cotton Fiber Growth and Development 2. Changes in Cell Diameter and Wall Birefringence. Journal of Cotton Science, 4, 97-104.

[5] Meinert, M.C. and Delmer, D.P. (1977) Changes in Biochemical Composition of the Cell Wall of the Cotton Fiber during Development. Plant Physiology, 59, 1088-1097. https://doi.org/10.1104/pp.59.6.1088

[6] Abdurakhmonov, I.Y., Buriev, Z.T., Saha, S., Jenkins, J.N., Abdukarimov, A. and Pepper, A.E. (2014) Phytochrome RNAi Enhances Major Fibre Quality and Agronomic Traits of the Cotton Gossypium hirsutum L. Nature Communications, 5, 3062. https://doi.org/10.1038/ncomms4062

[7] Abdurakhmonov, I.Y., Ayubov, M.S., Ubaydullaeva, K.A., Buriev, Z.T., Shermatov, S.E., Ruziboev, H.S., Shapulatov, U.M., Saha, S., Ulloa, M., Yu, J.Z., Percy, R.G., Devor, E.J., Sharma, G.C., Sripathi, V.R., Kumpatla, S.P., van der Krol, A., Kater, H.D., Khamidov, K., Salikhov, S.I., Jenkins, J.N., Abdukarimov, A. and Pepper, A.E. (2016) RNA Interference for Functional Genomics and Improvement of Cotton (Gossypium sp.). Frontiers in Plant Science, 7, PMC4762190. https://doi.org/10.3389/fpls.2016.00202

[8] Kasperbauer, M.J. (2000) Cotton Fibre Length Is Affected by Far-Red Light Impinging on Developing Bolls. Crop Science, 40, 1673-1678.

https://doi.org/10.2135/cropsci2000.4061673x

[9] Wang, Z., Zhang, D., Wang, X., Tan, X., Guo, H. and Paterson, A.H. (2013b) A Whole-Genome DNA Marker Map for Cotton Based on the D-Genome Sequence of Gossypium raimondii L. G3: Genes, Genomes, Genetics, 3,1759-1767.

[10] Kosmidou-Dimitropoulou, K. (1986) Hormonal Influences on Fiber Development. Cotton Physiology, The Cotton Foundation, Memphis, TN, 361-373.

[11] Lee, J.J., Woodward, A.W. and Chen, Z.J. (2007) Gene Expression Changes and Early Events in Cotton Fibre Development. Annals of Botany, 100, 1391-1401. https://doi.org/10.1093/aob/mcm232

[12] Guan, X., Song, Q. and Chen, Z.J. (2014) Polyploidy and Small RNA Regulation of Cotton Fiber Development. Trends in Plant Science, 19, 516-528. https://doi.org/10.1016/j.tplants.2014.04.007

[13] Wang, Q.Q., Liu, F., Chen, X.S., Ma, X.J., Zeng, H.Q. and Yang, Z.M. (2010) Transcriptome Profiling of Early Developing Cotton Fiber by Deep-Sequencing Reveals 
Significantly Differential Expression of Genes in a Fuzzless/Lintless Mutant. Genomics, 96, 369-376. https://doi.org/10.1016/j.ygeno.2010.08.009

[14] Wang, Q., Zhu, Z., Ozkardesh, K. and Lin, C. (2013a) Phytochromes and Phytohormones: The Shrinking Degree of Separation. Molecular Plant, 6, 5-7. https://doi.org/10.1093/mp/sss102

[15] Abdurakhmonov, I.Y. (2001) Molecular Cloning and Characterization of Genomic Sequence Tags (GSTS) from the PHYA, PHYB, and HY5 Gene Families of Cotton (Gossypium Species). Thesis, Texas A\&M University, Texas.

[16] Wan, C.Y. and Wilkins, T.A. (1994) A Modified Hot Borate Method Significantly Enhances the Yield of High-Quality RNA from Cotton (Gossypium hirsutum L.). Analytical Biochemistry, 223, 7-12. https://doi.org/10.1006/abio.1994.1538

[17] Bolger, A.M., Lohse, M. and Usadel, B. (2014) Trimmomatic: A Flexible Trimmer for Illumina Sequence Data. Bioinformatics, 30, 2114-2120.

https://doi.org/10.1093/bioinformatics/btu170

[18] Zhang, T., Hu, Y., Jiang, W., Fang, L., Guan, X., Chen, J., et al. (2015) Sequencing of Allotetraploid Cotton (Gossypium hirsutum L. acc. TM-1) Provides a Resource for Fiber Improvement. Nature Biotechnology, 33, 531-537. https://doi.org/10.1038/nbt.3207

[19] Mortazavi, A., Williams, B.A., McCue, K., Schaeffer, L. and Wold, B. (2008) Mapping and Quantifying Mammalian Transcriptomes by RNA-Seq. Nature Methods, 5, 621-628. https://doi.org/10.1038/nmeth.1226

[20] Conesa, A., Götz, S., García-Gómez, J.M., Terol, J. and Talón, M. (2005) Blast2GO: a Universal Tool for Annotation, Visualization and Analysis in Functional Genomics Research. Bioinformatics, 21, 3674-3676.

https://doi.org/10.1093/bioinformatics/bti610

[21] Quevillon, E., Silventoinen, V., Pillai, S., Harte, N., Mulder, N., Apweiler, R. and Lopez, R. (2005) InterProScan: Protein Domains Identifier. Nucleic Acids Research, 33, W116-W120.

[22] Ashburner, M., Ball, C.A., Blake, J.A., Botstein, D., Butler, H., Cherry, J.M., Davis, A.P., Dolinski, K., Dwight, S.S., Eppig, J.T., Harris, M.A., Hill, D.P., Issel-Tarver, L., Kasarskis, A., Lewis, S., Matese, J.C., Richardson, J.E., Ringwald, M., Rubin, G.M. and Sherlock, G. (2000) Gene Ontology: Tool for the Unification of Biology. Nature Genetics, 25, 25-29. https://doi.org/10.1038/75556

[23] Fisher, R.A. (1925) Statistical Methods for Research Workers. Genesis Publishing Pvt Ltd., Delhi.

[24] Auer, P.L. and Doerge, R.W. (2010) Statistical Design and Analysis of RNA Sequencing Data. Genetics, 185, 405-416. https://doi.org/10.1534/genetics.110.114983

[25] Subramanian, A., Tamayo, P., Mootha, V.K., Mukherjee, S., Ebert. B.L., Gillette, M.A., Paulovich, A., Pomeroy, S.L., Golub, T.R., Landet, E.S. and Mesirov, J.P. (2005) Gene Set Enrichment Analysis: A Knowledge-Based Approach for Interpreting Genome-Wide Expression Profiles. Proceedings of the National Academy of Sciences of the United States of America, 102, 15545-15550. https://doi.org/10.1073/pnas.0506580102

[26] Kanehisa, M. and Goto, S. (2000) KEGG: Kyoto Encyclopedia of Genes and Genomes. Nucleic Acids Research, 28, 27-30. https://doi.org/10.1093/nar/28.1.27

[27] Fu, W., Shen, Y., Hao, J., Wu, J., Ke, L., Wu, C., Huang, K., Luo, B., Xu, M., Cheng, X., Zhou, X., Sun, J., Xing, C. and Sun, Y. (2015) Acyl-CoA N-Acyltransferase Influences Fertility by Regulating Lipid Metabolism and Jasmonic Acid Biogenesis in Cotton. Scientific Reports, 5, 11790. https://doi.org/10.1038/srep11790 
[28] Livak, K.J. and Schmittgen, T.D. (2001) Analysis of Relative Gene Expression Data Using Real-Time Quantitative PCR and the $2^{-\Delta \Delta \mathrm{CT}}$ Method. Methods, 25, 402-408. https://doi.org/10.1006/meth.2001.1262

[29] Ding, M., Chen, J., Jiang, Y., Lin, L., Cao, Y., Wang, M., Zhang, Y., Rong, J. and Ye, W. (2015) Genome-Wide Investigation and Transcriptome Analysis of the WRKY Gene Family in Gossypium. Molecular Genetics and Genomics, 290, 151-171. https://doi.org/10.1007/s00438-014-0904-7

[30] Krochko, J.E., Abrams, G.D., Loewen, M.K., Abrams, S.R. and Cutler, A.J. (1998) (+)-Abscisic Acid 8-Hydroxylase Is a Cytochrome P450 Monooxygenase. Plant Physiology, 118, 849-860. https://doi.org/10.1104/pp.118.3.849

[31] Saito, S., Hirai, N., Matsumoto, C., Ohigashi, H., Ohta, D., Sakata, K. and Mizutani, M. (2004) Arabidopsis CYP707As Encode (+)-Abscisic Acid 8'-Hydroxylase, a Key Enzyme in the Oxidative Catabolism of Abscisic Acid. Plant Physiology, 134, 1439-1449. https://doi.org/10.1104/pp.103.037614

[32] Lodish, H., Berk, A., Zipursky, S.L., Matsudaira, P., Baltimore, D. and Darnell, J. (2000) The Dynamic Plant Cell Wall, Molecular Cell Biology. 4th Edition, W. H. Freeman and Company, New York.

[33] Lamport, D.T., Kieliszewski, M.J., Chen, Y. and Cannon, M.C. (2011) Role of the Extensin Superfamily in Primary Cell Wall Architecture. Plant Physiology, 156, 11-19. https://doi.org/10.1104/pp.110.169011

[34] Jiménez-López, J.C., de Dios Alche, J. and Rodríguez-García, M.I. (2011) Systematic and Phylogenetic Analysis of the Ole e 1 Pollen Protein Family Members in Plants: INTECH Open Access Publisher.

[35] Jiang, S.-Y., Jasmin, P.X.H., Ting, Y.Y. and Ramachandran, S. (2005) Genome-Wide Identification and Molecular Characterization of Ole_e_I, Allerg_1 and Allerg_2 Domain-Containing Pollen-Allergen-Like Genes in Oryza sativa. DNA Research, 12, 167-179. https://doi.org/10.1093/dnares/dsi005

[36] Bruex, A., Kainkaryam, R.M., Wieckowski, Y., Kang, Y.H., Bernhardt, C., Xia, Y., Zheng, X., Wang, J.Y., Lee, M.M., Benfey, P., Woolf, P.J. and Schiefelbein, J. (2012) A Gene Regulatory Network for Root Epidermis Cell Differentiation in Arabidopsis. PLOS Genetics, 8, e1002446. https://doi.org/10.1371/journal.pgen.1002446

[37] Van Hengel, A.J. and Roberts, K. (2003) AtAGP30, an Arabinogalactan-Protein in the Cell Walls of the Primary Root, Plays a Role in Root Regeneration and Seed Germination. The Plant Journal, 36, 256-270. https://doi.org/10.1046/j.1365-313X.2003.01874.x

[38] Rao, A.Q., Irfan, M., Saleem, Z., Nasir, I.A., Riazuddin, S. and Husnain, T. (2011) Overexpression of the Phytochrome B Gene from Arabidopsis thaliana Increases Plant Growth and Yield of Cotton (Gossypium hirsutum). Journal of Zhejiang University-Science B, 12, 326-334. https://doi.org/10.1631/jzus.B1000168

[39] Wang, H. and Deng, X.W. (2004) Phytochrome Signaling Mechanism in the Arabidopsis Book 3, 1-28.

[40] Kushanov, F.N., Pepper, A.E., Yu, J.Z., Buriev, Z.T., Shermatov, S.E., Saha, S., Ulloa, M., Jenkins, J.N., Abdukarimov, A. and Abdurakhmonov, I.Y. (2016) Development, Genetic Mapping and QTL Association of Cotton PHYA, PHYB, and HY5-Specific CAPS and dCAPS Markers. BMC Genetics, 17, 141. https://doi.org/10.1186/s12863-016-0448-4

[41] Yu, J., Yu, S., Gore, M., Wu, M., Zhai, H., Li, X., Fan, S., Song, M. and Zhang, J. (2013) Identification of Quantitative Trait Loci across Interspecific F2, F2:3 and Testcross Populations for Agronomic and Fiber Traits in Tetraploid Cotton. Eu- 
phytica, 191, 375-389. https://doi.org/10.1007/s10681-013-0875-5

[42] Brill, E., Van Thournout, M., White, R.G., Llewellyn, D., Campbell, P.M., Engelen, S., Ruan, Y.L., Arioli, T. and Furbank, R.T. (2011) A Novel Isoform of Sucrose Synthase Is Targeted to the Cell Wall during Secondary Cell Wall Synthesis in Cotton Fiber. Plant Physiology, 157, 40-54. https://doi.org/10.1104/pp.111.178574

[43] Chen, A., He, S., Li, F., Li, Z., Ding, M., Liu, Q. and Rong, J. (2012) Analyses of the Sucrose Synthase Gene Family in Cotton: Structure, Phylogeny and Expression Patterns. BMC Plant Biology, 12, 85. https://doi.org/10.1186/1471-2229-12-85

[44] Bai, W.-Q., Xiao, Y.-H., Zhao, J., Song, S.-Q., Hu, L., Zeng, J.-Y., Li, X.-B., Hou, L., Luo, M., Li, D.-M. and Pei, Y. (2014) Gibberellin Overproduction Promotes Sucrose Synthase Expression and Secondary Cell Wall Deposition in Cotton Fibers. PLoS ONE, 9, e96537. https://doi.org/10.1371/journal.pone.0096537

[45] Klein, M. and Papenbrock, J. (2004) The Multi-Protein Family of Arabidopsis Sulphotransferases and Their Relatives in Other Plant Species. Journal of Experimental Botany, 55, 1809-1820. https://doi.org/10.1093/jxb/erh183

[46] Wang, M., Liu, X., Wang, R., Li, W., Rodermel, S. and Yu, F. (2012) Overexpression of a Putative Arabidopsis BAHD Acyltransferase Causes Dwarfism That Can Be Rescued by Brassinosteroid. Journal of Experimental Botany, 63, 5787-5801. https://doi.org/10.1093/jxb/ers227

[47] Davis, L.A. and Addicott, F.T. (1972) Abscisic Acid: Correlations with Abscission and with Development in the Cotton Fruit. Plant Physiology, 49, 644-648. https://doi.org/10.1104/pp.49.4.644

[48] Shi, Y.-H., Zhu, S.-W., Mao, X.-Z., Feng, J.-X., Qin, Y.-M., Zhang, L., Cheng, J., Wei, L.-P., Wang, Z.-Y. and Zhu, Y.-X. (2006) Transcriptome Profiling, Molecular Biological, and Physiological Studies Reveal a Major Role for Ethylene in Cotton fiber Cell Elongation. Plant Cell, 18, 651-664. https://doi.org/10.1105/tpc.105.040303

[49] Binder, B.M., Walker, J.M., Gagne, J.M., Emborg, T.J., Hemmann, G., Bleecker, A.B. and Vierstra, R.D. (2007) The Arabidopsis EIN3 Binding F-Box Proteins EBF1 and EBF2 Have Distinct But Overlapping Roles in Ethylene Signaling. Plant Cell, 19, 509-523. https://doi.org/10.1105/tpc.106.048140

[50] Yang, Z., Tian, L., Latoszek-Green, M., Brown, D. and Wu, K. (2005) Arabidopsis ERF4 Is a Transcriptional Repressor Capable of Modulating Ethylene and Abscisic Acid Responses. Plant Molecular Biology, 58, 585-596. https://doi.org/10.1007/s11103-005-7294-5

[51] Wan, Q., Zhang, H., Ye, W., Wu, H. and Zhang, T. (2014) Genome-Wide Transcriptome Profiling Revealed Cotton Fuzz Fiber Development Having a Similar Molecular Model as Arabidopsis Trichome. PLoS ONE, 9, e97313. https://doi.org/10.1371/journal.pone.0097313

[52] Narusaka, M., Seki, M., Umezawa, T., Ishida, J., Nakajima, M., Enju, A. and Shinozaki, K. (2004) Crosstalk in the Responses to Abiotic and Biotic Stresses in Arabidopsis: Analysis of Gene Expression in Cytochrome P450 Gene Superfamily by cDNA Microarray. Plant Molecular Biology, 55, 327-342. https://doi.org/10.1007/s11103-004-0685-1

[53] Miao, Q., Deng, P., Saha, S., Jenkins, N.J, Hsu, C.-Y., Abdurakhmonov, I.Y., Buriev, Z.T., Pepper, A. and Ma, D.-P. (2017) Genome-Wide Identification and Characterization of microRNAs Differentially Expressed in Fibers in a Cotton Phytochrome A1 RNAi Line. PLoS ONE, 12, e0179381. https://doi.org/10.1371/journal.pone.0179381

[54] Nelson, D.R., Ming, R., Alam, M. and Schuler, M.A. (2008) Comparison of Cytoch- 
rome P450 Genes from Six Plant Genomes. Tropical Plant Biology, 1, 216-235. https://doi.org/10.1007/s12042-008-9022-1

[55] Jensen, K., Jensen, P.E. and Møller, B.L. (2011) Light-Driven Cytochrome p450 Hydroxylations. ACS Chemical Biology, 6, 533-539. https://doi.org/10.1021/cb100393j

[56] Chinnusamy, V., Schumaker, K. and Zhu, J.K. (2004) Molecular Genetic Perspectives on Cross-Talk and Specificity in Abiotic Stress Signalling in Plants. Journal of Experimental Botany, 55, 225-236. https://doi.org/10.1093/jxb/erh005

[57] Zhu, W., Miao, Q., Sun, D., Yang, G., Wu, C., Huang, J. and Zheng, C. (2012) The Mitochondrial Phosphate Transporters Modulate Plant Responses to Salt Stress via Affecting ATP and Gibberellin Metabolism in Arabidopsis thaliana. PloS ONE, 7 , e43530. https://doi.org/10.1371/journal.pone.0043530

\section{Submit or recommend next manuscript to SCIRP and we will provide best} service for you:

Accepting pre-submission inquiries through Email, Facebook, LinkedIn, Twitter, etc. A wide selection of journals (inclusive of 9 subjects, more than 200 journals)

Providing 24-hour high-quality service

User-friendly online submission system

Fair and swift peer-review system

Efficient typesetting and proofreading procedure

Display of the result of downloads and visits, as well as the number of cited articles

Maximum dissemination of your research work

Submit your manuscript at: http://papersubmission.scirp.org/

Or contact ajps@scirp.org 